\title{
TREINAMENTO FÍSICO: LESÕES E PREVENÇÃO. UM ESTUDO COMPARATIVO DA ROTINA DE JUDOCAS E BAILARINOS
}

\author{
Larissa de Oliveira ${ }^{1}$ \\ Ana Carolini Corrêa ${ }^{2}$ \\ Cássia Lais Gonçalves Amaral ${ }^{3}$ \\ Luara Aparecida Amaral ${ }^{4}$ \\ Maria das Graças Sandi Magalhães ${ }^{5}$
}

Resumo: Este artigo destaca a importância das atividades físicas preventivas, com acompanhamento de fisioterapeuta, para evitar lesões causadas por sequências de treinamento físico intensivo. A partir de estudo de caso, de caráter qualitativo e comparativo, com judocas e bailarinos que treinam na cidade de São José dos Campos, conclui-se que o treinamento dado aos atletas do judô prioriza menos a prevenção do que o treinamento que é proporcionado às bailarinas e bailarinos.

Palavras-chave: Lesões musculares; Prevenção; Treinamento físico; Fisioterapia preventiva.

\footnotetext{
${ }^{1}$ Discente Fisioterapia/Faculdade Anhanguera de São José dos Campos, Brasil. E-mail: lari-oliveira@live.com. 2 Discente Fisioterapia/Faculdade Anhanguera de São José dos Campos, Brasil. E-mail: correacaroliniana@gmail.com.

3 Discente Fisioterapia/Faculdade Anhanguera de São José dos Campos, Brasil. E-mail: cassialais@hotmail.com.

4 Discente Fisioterapia/Faculdade Anhanguera de São José dos Campos, Brasil. E-mail: luaraamaraljc@gmail.com.

5 Docente Fisioterapia, Pedagogia/Faculdade Anhanguera de São José dos Campos, Brasil. E-mail: maria.sandi@anhanguera.com.
} 